\title{
Dynamics of productivity in naturally structured macroalgal assemblages: importance of canopy structure on light-use efficiency
}

\author{
Leigh W. Tait*, David R. Schiel \\ Marine Ecology Research Group, School of Biological Sciences, University of Canterbury, Private Bag 4800, Christchurch, \\ New Zealand
}

\begin{abstract}
Macroalgae are undoubtedly a major supplier of organic carbon to marine food webs, yet few studies have attempted to examine primary production in complex macroalgal communities. Many studies have tested the photosynthetic characteristics of single species with little attention given to the associated algal assemblages. The role of canopy structure and species diversity in these assemblages will help in understanding the role of biodiversity in enhancing ecosystem function. In the present study, photosynthesis-irradiance relationships ( $P$-E curves) of intact intertidal algal assemblages showed no signs of saturation at high irradiance levels, as is typically seen in singlespecies curves. Canopy-forming species appear to play a vital role in enhancing overall assemblage net photosynthesis, particularly at high irradiances $\left(>1500 \mu \mathrm{mol} \mathrm{m} \mathrm{m}^{-2} \mathrm{~s}^{-1}\right.$ ), with the loss of canopy species causing up to a $50 \%$ decline in the photosynthetic rate of assemblages. There is also evidence that the mechanisms of light use are significantly different in intact assemblages because they do not act as the sum of their parts at high irradiance levels. Furthermore, with greater structural complexity, net photosynthesis of the assemblage is enhanced, particularly at high irradiance. The present study demonstrates the importance of using realistic species compositions and assemblage structure to identify the potential mechanisms enhancing function with increasing diversity. A better understanding of light-use efficiency within macroalgal communities underpins the role of biodiversity and community structure in these ecosystems and the potential effects of species loss on various forms of ecosystem function.
\end{abstract}

KEY WORDS: Macroalgae $\cdot$ Net photosynthesis $\cdot$ Assemblage $\cdot$ Irradiance $\cdot$ Canopy

\section{INTRODUCTION}

Macroalgae are the dominant primary producers of temperate nearshore regions and are most likely the main supplier of organic matter to the surrounding ecosystem (Mann 1973). Large macroalgae also provide habitat for a wide range of sub-canopy algae and invertebrates (Bertness et al. 1999, Bruno et al. 2003, Lilley \& Schiel 2006, Schiel 2006). Macroalgae therefore provide 2 vital roles in marine ecosystems, those of habitat provision and primary production, which makes them essential to overall ecosystem function (Bruno et al. 2003, Schiel 2006). Loss or reductions in abundance of primary producers have the potential to alter the quantity and quality of carbon fixation (Shaver et al. 2000). To understand the potential impacts of algal species losses, therefore, it is necessary to have an accurate estimation of their contributions to ecosystem function, not only in terms of facilitation, but also of primary production.

Traditionally, macroalgal primary production research in the marine environment has focused on measurements of physical growth in situ (Mann 1972, 1973) or physiological oxygen production/carbon fixation in laboratory settings (Littler \& Littler 1980, Littler $\&$ Arnold 1982). Although useful for identifying sea- 
sonal biomass accumulation, in situ measurements of frond elongation or frond area increments fail to take account of processes such as abrasion, herbivory, reproduction, and sloughing in estimations of primary productivity (Larkum 1986). Likewise, short-term incubations measuring carbon assimilation (or oxygen production) are often performed using excised tissue of macroalgal specimens (Flores-Moya et al. 1995, Gómez et al. 1997) and extrapolating these to whole plants. Furthermore, laboratory measurements of primary production in single specimens often fail to account for inter- and intra-species interactions among algal species that occur under natural conditions (Middelboe \& Binzer 2004). Recent research has indicated the important influence of algal density and diversity on the use of light (Binzer \& Sand-Jensen 2002, Middelboe \& Binzer 2004) and reveals the problems associated with measuring productivity in single specimens or excised tissue. Light attenuation through canopy species results in greater filtration of light and, therefore, a more linear relationship between productivity and irradiance compared to saturation curves seen in single species incubations (Binzer \& SandJensen 2002). To gain a better understanding of the primary production dynamics in macroalgae, it may be necessary to adapt an assemblage-based approach that takes into account resource partitioning. The productivity of in situ macroalgal assemblages during emersion indicates that canopy-forming macroalgae and their sub-canopy assemblages are under the control of light and temperature (Golléty et al. 2008). In situ incubations of whole assemblages are therefore likely to give greater insight into the dynamics of productivity in natural assemblages than are incubations of single thalli or monospecific stands. Furthermore, nutrient uptake efficiency has been shown to be lower in macroalgal monocultures compared to diverse macroalgal assemblages (Bracken \& Stachowicz 2006). It is probable, therefore, that the efficiency of light use will also depend on the diversity and structure within macroalgal assemblages. Consequently, the effects of losing species will depend on the natural composition of communities and the identity of the species lost to communities (e.g. Lilley \& Schiel 2006, Schiel 2006).

The relationship between plant (or algal) biodiversity and primary productivity has received a great deal of attention in the recent ecological literature (Tilman et al. 1997). Overall, the evidence points to an enhancement of primary productivity with increasing biodiversity (Stachowicz et al. 2007), but the mechanisms by which this occurs are debated (Huston 1997), as are the results (Huston et al. 2000). Many experiments have tested the effects of plant or algal diversity in artificial settings (i.e. experiments often use randomly generated species assemblages), with little appreciation of the structuring within natural assemblages. Randomized mesocosm experiments may neglect important interactions between species commonly co-existing, such as those involving nutrient use (Bracken \& Stachowicz 2006) and canopy layering effects (Middelboe \& Binzer 2004). The role of canopy structure and species composition on primary production dynamics may help our understanding of the mechanisms potentially enhancing production in natural assemblages.

The shores of southern New Zealand are ideal places to test these aspects of structure and function. The intertidal zone of semi-exposed shores is dominated by fucoid algae, particularly Hormosira banksii and Cystophora torulosa (Schiel 2006). H. banksii is very tolerant of desiccation, whereas C. torulosa is susceptible to burn-off during the summer months when exposed to low tide (Lilley \& Schiel 2006). H. banksii is often affected by human pedestrian disturbance (Keough \& Quinn 1998, Schiel \& Taylor 1999) and is broken easily by wave damage during storms. Given the ever-increasing amount of human disturbance on algal-dominated communities through pedestrian disturbance (Keough \& Quinn 1998, Schiel \& Taylor 1999), selective removal of species (Kingsford et al. 1991), and sedimentation (Schiel et al. 2006), examining the potential effects of canopy loss is increasingly relevant. The loss of $H$. banksii and $C$. torulosa has been shown to cause a reduction in the cover and diversity of sub-canopy algae and invertebrates in the mid-high shore environment (Lilley \& Schiel 2006). In some cases, recovery of canopies can take several years (Underwood 1998, Schiel 2006). The resulting loss of canopy biomass from various disturbances could have major consequences not only to community composition, but to overall primary production.

Habitat-dominating perennial species such as fucoid algae may be less productive than many laminarian species, but on many New Zealand reefs they contribute a dominant proportion of the standing biomass year round (Schiel 1990). The loss of habitatdominating macroalgae is often associated with a dramatic change in the composition of sub-canopy communities (Bertness et al. 1999, Lilley \& Schiel 2006, Schiel 2006, Arkema et al. 2009), yet the impacts of canopy loss on primary productivity has received less attention. Understanding the dynamics of productivity within these assemblages may shed some light on the mechanism by which diversity may enhance one of the most important functions of communities and ecosystems.

In the present study, our aim was to understand the role of canopies, assemblage structure, and their interaction on the dynamics of primary productivity. We used natural macroalgal assemblages taken from the 
field and tested under controlled laboratory conditions to evaluate primary production and light-use efficiency using measurements of net photosynthesis, or oxygen evolution. We tested the null hypothesis that the canopy and assemblage structure have no effect on net photosynthesis in algal assemblages.

\section{MATERIALS AND METHODS}

Net photosynthesis of assemblage components. Before tests of entire assemblage photosynthesis were done, the net photosynthetic rates of the assemblage components were determined. Oxygen evolution was used to determine the net photosynthesis of the assemblage components, and is a commonly used proxy for primary production (e.g. Littler \& Arnold 1982). The main components of the assemblage were the dominant canopy species Hormosira banksii, the sub-canopy fucoid Cystophora torulosa, and the basal turf assemblage, dominated by Corallina officinalis (hereafter referred to as the 'basal assemblage'). The net photosynthesis of a single thallus was tested in $H$. banksii and C. torulosa to understand the photosynthetic properties of individual species. The basal assemblage, made up predominantly of $C$. officinalis and various ephemeral algae (particularly the brown alga Colpomenia bulosa and the red alga Champia novae-zelandiae), was examined by removing a small section of substratum (approximately $10 \times 10 \mathrm{~cm}$ ) with the algae attached. Net photosynthesis of $H$. banksii, C. torulosa, and the basal assemblage was determined by incubating algae in sealed incubation chambers under a range of irradiances and measuring net increases in oxygen. Photosynthesis-irradiance relationships ( $P$-E curves) were generated. Temperature was controlled using a water jacket that surrounded the chamber. Water within the jacket was pumped from a temperature-controlled water bath to the chamber using a submerged magnetic pump. Chambers were kept at a constant $15^{\circ} \mathrm{C}$, which was verified using internal temperature loggers. Chambers used for single thallus incubations were $15 \mathrm{~cm}$ in diameter and $15 \mathrm{~cm}$ high to accommodate an entire algal thallus. To prevent boundary layers forming on the algal surface (which could potentially limit photosynthesis), chambers were constantly mixed using a magnetic flea. Water samples were extracted by $1 \mathrm{ml}$ syringes (14 ml taken for each replicate across all levels of irradiance) and oxygen concentration was measured in a Clark-type oxygen electrode (Strath Kelvin Microcell MC100). Samples were taken half-hourly for photosynthesis and respiration measurements over $1 \mathrm{~h}$ for each irradiance level, with an incubation series on each assemblage lasting approximately $7 \mathrm{~h}$.
Algae were incubated under various light intensities using a Phillips Discharge metal halide lamp calibrated to photosynthetically active radiation (PAR) wavelengths, with irradiance adjusted using neutral density filters to give 5 levels of irradiance $(150,300$, 800, 1500, and $2000 \mu \mathrm{mol} \mathrm{m} \mathrm{m}^{-2} \mathrm{~s}^{-1}$ ). Dark respiration was obtained by covering the chamber to omit light. Measurements of dark respiration were performed at least $1 \mathrm{~h}$ after algae had been exposed to light to minimize the inclusion of photorespiration in the results. Measurements of respiration were used only to obtain baseline respiration rates and were not incorporated into values for net photosynthesis. In total, 6 replicates $(n=6)$ of each assemblage component were incubated under each level of irradiance. Following incubations, algae were dried for $24 \mathrm{~h}$ in a conventional oven at $50^{\circ} \mathrm{C}$ and dry weights were recorded.

These single-thallus tests were done to identify the dynamics of net photosynthesis in the assemblage components and provided a baseline for comparison with intact algal assemblages. It also provided a means of testing whether net photosynthesis of these assemblages is simply a sum of the parts or whether there are other factors playing a role in overall net photosynthesis.

Macroalgal assemblage net photosynthesis and canopy removal. To test the importance of structure in natural assemblages, net photosynthesis was then tested in intact macroalgal communities. Using a hammer and chisel, macroalgal assemblages were removed from the reef with the substratum attached (approximately $20 \times 20 \mathrm{~cm}$ of substratum). These were taken back to the laboratory where all incubations were done. The methodology used above ('Net photosynthesis of assemblage components') for single species was also used for the macroalgal assemblages. To accommodate the macroalgal assemblages, large incubation chambers were used. These were made of an $8 \mathrm{~mm}$ thick clear Perspex tube $(30 \mathrm{~cm}$ high, $25 \mathrm{~cm}$ diameter), with a $10 \mathrm{~mm}$ thick clear Perspex base plate and lid (Tait \& Schiel 2010). Unlike the chambers used for single-species incubations, these chambers did not have a cooling water jacket, so temperature was controlled by placing chambers in a constant temperature water bath and maintained at $15^{\circ} \mathrm{C}$ (verified using internal temperature loggers). The same light source and irradiance regime used in the single-thallus incubations were used for the assemblages. Chambers were mixed using a submerged magnetic water pump that circulated water within the chamber in a vortex motion. Water samples of $1 \mathrm{ml}$ were taken from taps situated in the lid of the chamber. Due to the size of the assemblages, the water in the chambers was exchanged after incubations at 2 irradiance levels, to ensure that no nutrients became limiting. All visible 
invertebrates were removed from the community before incubations.

The volume displaced by the substratum was accounted for after all incubations to determine the oxygen evolved per liter of water. After intact assemblage incubations were completed, the dominant canopy and sub-canopy species were sequentially removed from the assemblage and oxygen production measured from a series of experiments after the removal of each component. The effect of species loss was tested by removing one or both of the dominant fucoid algae, Cystophora torulosa and Hormosira banksii. The order of removal was then altered to determine the role of each species within the assemblage. Also, the role of the sub-canopy was tested by first removing the basal assemblage (dominated by Corallina officinalis and its attached epiphytes), and then removing understory $C$. torulosa. This left only $H$. banksii (the dominant canopy species) in the final incubation series. In total, 8 replicates $(n=8)$ were used in each treatment and removal order.

To compare the net photosynthesis of algae incubated alone to that of intact assemblages, an additive value was derived from the oxygen production of the 3 assemblage components (Hormosira banksii, Cystophora torulosa, and the basal assemblage). Although the basal assemblage was sometimes composed of several species, these were found in very low amounts and differed significantly between replicates. Therefore, all the low-lying species were grouped together as the basal assemblage for analysis. Values were calculated at 5 levels of irradiance $(150,300,800,1500$, and $2000 \mu \mathrm{mol} \mathrm{m} \mathrm{m}^{-2} \mathrm{~s}^{-1}$ ) by first weighting the net photosynthesis of each component by its average contribution to the assemblage (on a dry weight basis), then adding the 3 net photosynthesis values together. The average contribution of each species to the assemblage was determined by the relative species weights in the incubations of intact communities. This allowed comparisons to determine if an assemblage acts as the sum of its parts, or if species interactions within naturally occurring assemblages have a significant effect on overall net photosynthesis.

The influence of canopy structure on overall photosynthesis was tested using data from previous removal experiments (as described in 'Materials and methods - Macroalgal assemblage net photosynthesis and canopy removal'). Canopy, sub-canopy, and basal assemblage removal experiments were used to determine the effects that the number of structural layers had on net photosynthesis at various levels of irradiance. All the assemblages that we tested, both manipulated and intact, were categorized into 3 types: (1) intact assemblage of 3 layers (i.e. Hormosira banksii, Cystophora torulosa, and the basal assemblage), (2) all combinations of 2 layers, and (3) the 3 types of 1 assemblage layer. We averaged data across all combinations of 2-layer assemblages, and across individual components of 1 structural layer. All net photosynthetic data were standardized by the dry weight of algae within the assemblages and were analyzed at 3 levels of irradiance $\left(800,1500\right.$, and $\left.2000 \mu \mathrm{mol} \mathrm{m} \mathrm{m}^{-2} \mathrm{~s}^{-1}\right)$.

Statistical analysis. Photosynthesis curves of single assemblage components net photosynthetic rate $\left(P_{\mathrm{c}}\right)$ were fitted against irradiance (i.e. $P$-E curves) using the exponential relationship described by Walsby (1997):

$$
P_{\mathrm{C}}=P_{\mathrm{m}}\left[1-\exp \left(-\alpha E / P_{\mathrm{m}}\right)\right]+R+\beta E
$$

where $P_{\mathrm{m}}$ is the maximum photosynthetic rate at lightsaturating irradiances, $E$ is irradiance level, $R$ is the rate of respiratory oxygen production, $\alpha$ is the gradient observed at light-limiting irradiances, and $\beta$ is the negative gradient due to photoinhibition at high irradiances. $\alpha$ was calculated as the slope of a linear regression between 0 and $100 \mu \mathrm{mol} \mathrm{m}{ }^{-2} \mathrm{~s}^{-1}$ for each replicate thallus or assemblage. $\beta$ was calculated as the slope of a linear regression between 1500 and $2000 \mu \mathrm{mol} \mathrm{m} \mathrm{m}^{-2} \mathrm{~s}^{-1}$, as this is where photoinhibition typically occurred, for each replicate thallus and assemblage. $\beta$ was then fitted into the model at irradiances $>1500 \mu \mathrm{mol} \mathrm{m} \mathrm{m}^{-2} \mathrm{~s}^{-1}$. Furthermore, $E_{\mathrm{C}}$, the irradiance at compensation (i.e. where net photosynthesis $=0$ ), and $E_{k}$, the irradiance at saturation, were calculated for the assemblage components. The differences in these photosynthetic parameters between species were examined using 1-way ANOVA and Tukey's post-hoc tests.

Photosynthesis characteristics of macroalgal assemblages were analyzed by calculating the same photosynthetic parameters (with the exception of $\beta$ ) as used for assemblage components. The parameters used were $\alpha, \gamma$ (instead of $\beta$ ), $R, E_{\mathrm{C}}$, and $P_{2000}$, where $P_{2000}$ is the net photosynthesis at $2000 \mu \mathrm{mol} \mathrm{m} \mathrm{m}^{-2} \mathrm{~s}^{-1}$. Because saturation in photosynthesis did not occur in all assemblages, $P_{\mathrm{m}}$ could not always be calculated, as photosynthesis continued to rise across all irradiance levels. Therefore, the value of $P$ was restricted to the highest level of irradiance tested (i.e. $P_{2000}$, at $2000 \mu \mathrm{mol} \mathrm{m} \mathrm{m}^{-2}$ $\mathrm{s}^{-1}$ ). Furthermore, photoinhibition (or $\beta$ ) did not occur for all assemblages, and so could not be a factor in testing photoinhibition across the different assemblages. Hence, we designated a new parameter, arbitrarily termed $\gamma$, for the direction of change between 1500 and $2000 \mu \mathrm{mol} \mathrm{m} \mathrm{m}^{-2} \mathrm{~s}^{-1}$. Therefore, $\gamma$ can represent a positive (increase in net photosynthesis) or negative (photoinhibition) trend in photosynthesis of assemblages. Also, $E_{\mathrm{c}}$ was calculated for all assemblages, but due to the lack of saturation in some assemblages, $E_{k}$ was not calculated. The differences in these photosynthetic parameters between assemblages were examined using 1-way ANOVA and Tukey's post-hoc tests. 


\section{RESULTS}

The 3 dominant components of the macroalgal assemblages showed wide variation in net photosynthesis (Fig. 1). All 3 components showed typical saturation curves with irradiance up to $1500 \mu \mathrm{mol} \mathrm{m} \mathrm{m}^{-2} \mathrm{~s}^{-1}$. The P-E curves for Hormosira banksii and the basal assemblage both showed a decline in photosynthesis (i.e. photoinhibition) at high irradiance $\left(2000 \mu \mathrm{mol} \mathrm{m} \mathrm{m}^{-2}\right.$ $\mathrm{s}^{-1}$ ) and there was a significant difference in $\beta$ between species (Table 1). Tukey's post-hoc tests show a significant difference in $\beta$ between $H$. banksii and Cystophora torulosa $(q=4.9, \mathrm{p}<0.05)$. There was a significant difference in $\alpha$ between species, with C. torulosa showing the steepest initial rise in photosynthesis, followed by $H$. banksii, and then the basal assemblage. Tukey's post-hoc tests show a significant difference in $\alpha$ between $H$. banksii and C. torulosa ( $q=$ 9.9, p < 0.001), between $H$. banksii and the basal assemblage $(q=4.6, \mathrm{p}<0.05)$, as well as between C. torulosa and the basal assemblage $(q=14.4, \mathrm{p}<$

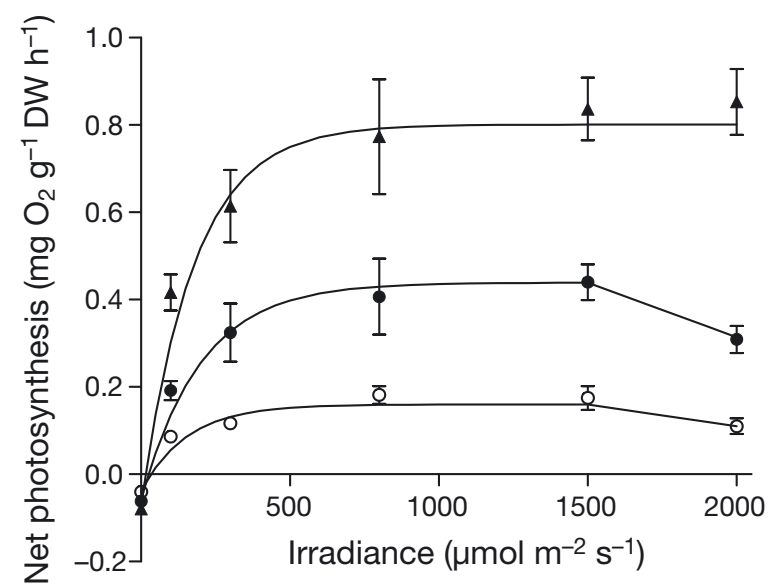

Fig. 1. Net photosynthesis $( \pm \mathrm{SE})$ of the 3 major components of Hormosira banksii-dominated assemblages: H. banksii $(\bullet)$, Cystophora torulosa ( $\mathbf{\Lambda})$, and the basal assemblage (o) (dominated by Corallina officianalis and other red and brown algae; see Table 2)
0.001). The fucoid algae C. torulosa and $H$. banksii had much higher $P_{\mathrm{m}}$ compared to the basal assemblage (average maximum of 0.837 and $0.44 \mathrm{mg} \mathrm{O}_{2} \mathrm{~g}^{-1} \mathrm{DW}$ $\mathrm{h}^{-1}$, respectively, vs. $0.18 \mathrm{mg} \mathrm{O}_{2} \mathrm{~g}^{-1} \mathrm{DW} \mathrm{h}^{-1}$ for the basal assemblage; DW is dry weight). Tukey's post-hoc tests show a significant difference in $P_{\mathrm{m}}$ between $H$. banksii and C. torulosa $(q=8.4, \mathrm{p}<0.001)$, between $H$. banksii and the basal assemblage $(q=6.1, \mathrm{p}<$ 0.001), as well as between $C$. torulosa and the basal assemblage $(q=12.79$, $p<0.001)$. There was an overall significant difference in respiration rates between the species, and much like the other parameters, C. torulosa had the highest respiration, followed by $H$. banksii and then the basal assemblage. Tukey's post-hoc tests show a significant difference between C. torulosa and the basal assemblage $(q=5.9, \mathrm{p}<0.01)$. $E_{\mathrm{c}}$ was significantly different between the assemblage components, with $C$. torulosa showing compensation at the lowest irradiance, followed by $H$. banksii and then the basal assemblage (Table 1). Tukey's post-hoc tests show a significant difference between $H$. banksii and $C$. torulosa $(q=3.7, \mathrm{p}<0.05)$ and between $C$. torulosa and the basal assemblage $(q=7.0, \mathrm{p}<0.001)$. There was no significant difference in $E_{k}$ between species.

Hormosira banksii and the basal assemblage formed the largest proportion of the biomass within these assemblages, with an average biomass of $33.34 \pm 9.8$ and $29.67 \pm 2.7 \mathrm{~g} \mathrm{DW}$, respectively (Table 2). Cystophora torulosa contributed the least to the assemblage, but had the greatest rate of net photosynthesis of the 3 components on a per-weight basis (average of $0.76 \mathrm{mg} \mathrm{O}_{2} \mathrm{~g}^{-1} \mathrm{DW} \mathrm{h}^{-1}$ at irradiance levels $>500 \mu \mathrm{mol}$ $\mathrm{m}^{-2} \mathrm{~s}^{-1}$ ). The basal assemblage was made up of predominantly Corallina officinalis, with trace amounts of Champia novae-zelandiae, Colpomenia bulosa, Leathesia difformis, and Jania micrarthrodia.

Intact assemblages had a $P$-E curve that was very different from the assemblage components, with no indication of saturation of photosynthesis (Fig. 2). Net

Table 1. Comparison of photosynthetic parameters (mean \pm SE) between species (Basal assemblage: basal turf assemblage, dominated by Corallina officinalis), including the initial slope $\alpha$, maximum net photosynthesis $\left(P_{\mathrm{m}}\right)$, respiration $(R)$, photoinhibition $(\beta)$, and irradiance at compensation $\left(E_{\mathrm{c}}\right)$ and at saturation $\left(E_{\mathrm{k}}\right)(\mathrm{n}=6$ for all components). Significance of differences between species tested by 1-way ANOVA. ns: not significant, na: not applicable

\begin{tabular}{|c|c|c|c|c|c|c|}
\hline & $\begin{array}{c}P_{\mathrm{m}} \\
\left(\mathrm{mg} \mathrm{O}_{2} \mathrm{~g}^{-1}\right. \\
\left.\mathrm{DW} \mathrm{h}^{-1}\right)\end{array}$ & $\begin{array}{c}R \\
\left(\mathrm{mg} \mathrm{O}_{2} \mathrm{~g}^{-1}\right. \\
\left.\mathrm{DW} \mathrm{h}^{-1}\right)\end{array}$ & $\alpha$ & $\beta$ & $\begin{array}{c}E_{\mathrm{c}} \\
(\mu \mathrm{mol} \\
\left.\mathrm{m}^{-2} \mathrm{~s}^{-1}\right)\end{array}$ & $\begin{array}{c}E_{\mathrm{k}} \\
(\mu \mathrm{mol} \\
\left.\mathrm{m}^{-2} \mathrm{~s}^{-1}\right)\end{array}$ \\
\hline Hormosira banksii & $0.44 \pm 0.062$ & $-0.06 \pm 0.017$ & $0.003 \pm 0.003$ & $-0.0004 \pm 0.003$ & $24.85 \pm 0.44$ & $873.8 \pm 32.45$ \\
\hline Cystophora torulosa & $0.84 \pm 0.067$ & $-0.08 \pm 0.019$ & $0.005 \pm 0.006$ & $0 \pm 0.004$ & $16.3 \pm 0.27$ & $836.3 \pm 21.31$ \\
\hline Basal assemblage & $0.18 \pm 0.039$ & $-0.04 \pm 0.023$ & $0.001 \pm 0.005$ & $-0.0001 \pm 0.0014$ & $32.5 \pm 0.42$ & $783.2 \pm 22.2$ \\
\hline \multicolumn{7}{|l|}{ ANOVA } \\
\hline $\mathrm{p}$ & $<0.0001$ & 0.0047 & $<0.0001$ & 0.012 & 0.0007 & ns \\
\hline$F_{2,12}$ & 40.9 & 8.6 & 33.9 & 6.2 & 12.4 & na \\
\hline
\end{tabular}


Table 2. Components of typical mid-shore intertidal assemblages (of approximate area $20 \times 20 \mathrm{~cm}$ ) and relative net photosynthesis (at $800 \mu \mathrm{mol} \mathrm{m} \mathrm{m}^{-2} \mathrm{~s}^{-1}$ ) per dry weight (DW) of algal material. Data are mean $\pm \mathrm{SE}$

\begin{tabular}{|c|c|c|c|}
\hline & $\begin{array}{l}\text { DW in } 20 \times 20 \mathrm{~cm} \\
\text { assemblage }(\mathrm{g})\end{array}$ & $\begin{array}{l}\text { Contribution to } \\
\text { assemblage (\%) }\end{array}$ & $\begin{array}{l}\text { Net photosynthesis } \\
\left(\mathrm{mg} \mathrm{O}_{2} \mathrm{~g}^{-1} \mathrm{DW} \mathrm{h}^{-1}\right)\end{array}$ \\
\hline \multicolumn{4}{|l|}{ Assemblage component } \\
\hline Hormosira banksii & $33.34 \pm 9.8$ & $46.3 \pm 10.5$ & $0.41 \pm 0.08$ \\
\hline Cystophora torulosa & $8.95 \pm 1.5$ & $12.4 \pm 2.2$ & $0.76 \pm 0.09$ \\
\hline Basal assemblage (total) & $29.67 \pm 2.7$ & $41.2 \pm 3.5$ & $0.18 \pm 0.05$ \\
\hline \multicolumn{4}{|c|}{ Basal assemblage components } \\
\hline Corallina officinalis & $27.07 \pm 2.0$ & $37.6 \pm 2.8$ & \\
\hline Champia novae-zelandiae & $1.12 \pm 0.3$ & $1.6 \pm 0.3$ & \\
\hline Colpomenia bulosa & $1.03 \pm 0.3$ & $1.43 \pm 0.3$ & \\
\hline Leathesia difformis & $0.4 \pm 0.05$ & $0.6 \pm 0.08$ & \\
\hline Jania micrarthrodia & $0.048 \pm 0.02$ & $0.06 \pm 0.03$ & \\
\hline
\end{tabular}

photosynthesis increased throughout the range of irradiance with no sign of photoinhibition, despite Hormosira banksii (which showed photoinhibition when incubated alone) being the dominant species. Removal of components had a significant effect on photosynthesis, and there was a significant effect of treatment on all photosynthetic parameters $(\alpha, \gamma, R$, $P_{2000}$, and $E_{\text {ci }}$ Table 3$)$. Removal of Cystophora toru-
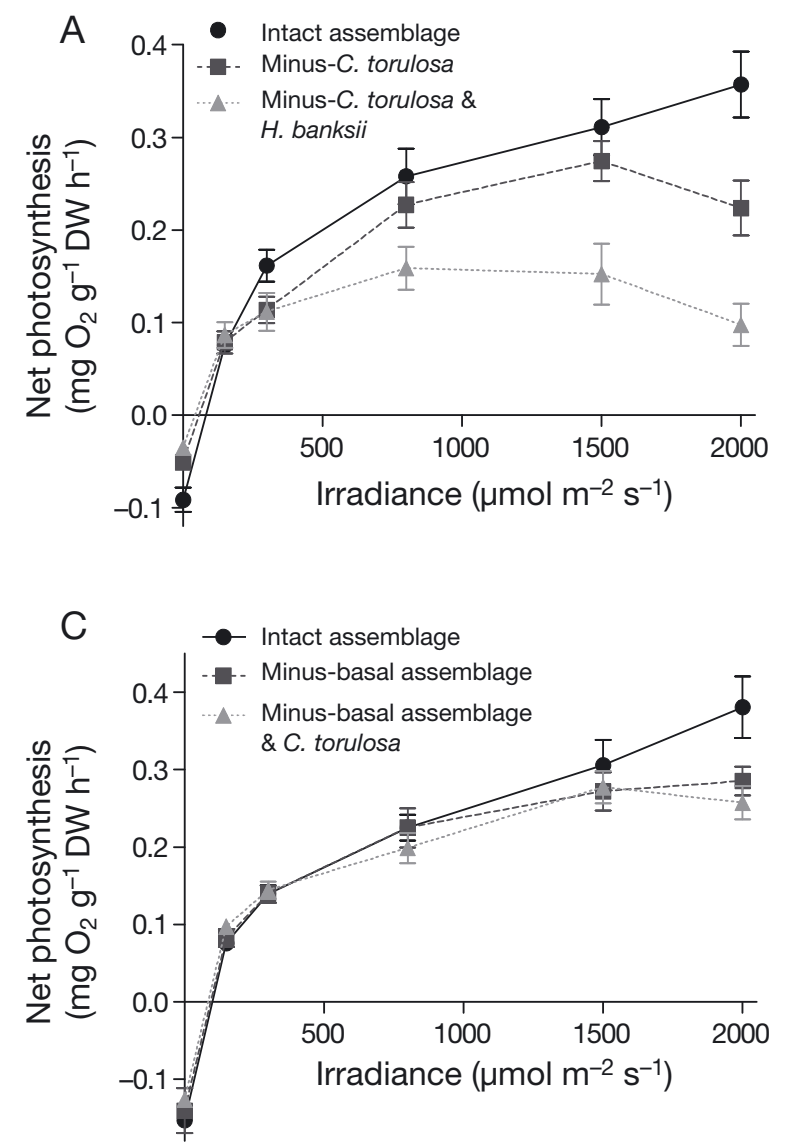

losa from the assemblage (Fig. 2A) resulted in a slight fall in net photosynthesis throughout most levels of irradiance, but was significantly lower than the intact assemblage at $2000 \mu \mathrm{mol} \mathrm{m} \mathrm{m}^{-2} \mathrm{~s}^{-1}$ (Tukey's post-hoc test: $q=5.7, p<0.01)$. In the absence of $C$. torulosa, the assemblage showed photoinhibition at high irradiance, as indicated by the significant difference in $\gamma$ between the intact assemblage and the minus-

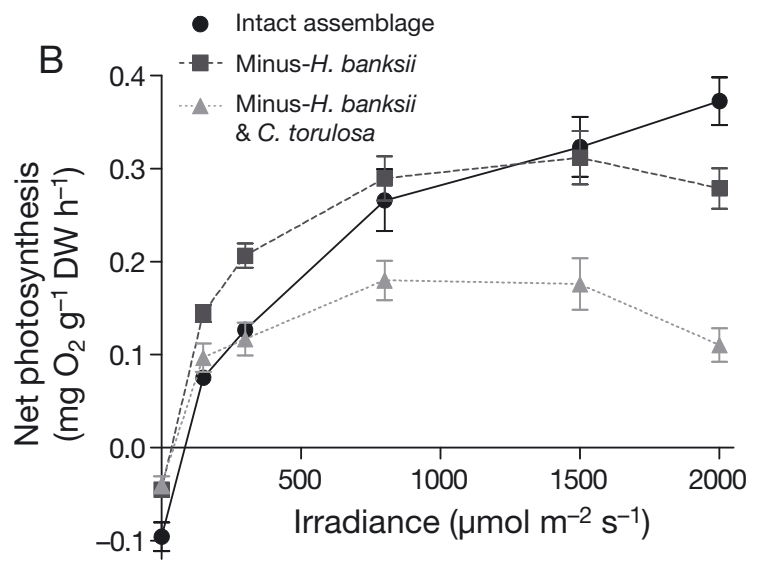

Fig. 2. Variation in net photosynthesis $( \pm \mathrm{SE})$ across irradiance levels in different structured assemblages. The removal order varied; (A) intact assemblage, minus Cystophora torulosa, and minus both C. torulosa and Hormosira banksii; (B) intact assemblage, minus $H$. banksii, and minus $H$. banksii and C. torulosa; (C) intact assemblage, minus basal assemblage, and minus C. torulosa. Net photosynthesis is standardized by dry weight of algae 
Table 3. Comparison of photosynthetic parameters (mean $\pm \mathrm{SE}$ ) between assemblages of various compositions, including the initial slope $\alpha$, net photosynthesis at irradiance $2000 \mu \mathrm{mol} \mathrm{m} \mathrm{m}^{-2} \mathrm{~s}^{-1}\left(P_{2000}\right)$, respiration $(R)$, the slope at high irradiance $(\gamma)$, and the irradiance at compensation $\left(E_{\mathrm{c}}\right)(\mathrm{n}=8$ for all treatments). Significance of differences between assemblages tested by 1 -way ANOVA

\begin{tabular}{|c|c|c|c|c|c|}
\hline Assemblage & $\begin{array}{c}P_{2000} \\
\left(\mathrm{mg} \mathrm{O}_{2} \mathrm{~g}^{-1}\right. \\
\left.\mathrm{DW} \mathrm{h}^{-1}\right)\end{array}$ & $\begin{array}{c}R \\
\left(\mathrm{mg} \mathrm{O}_{2} \mathrm{~g}^{-1}\right. \\
\left.\mathrm{DW} \mathrm{h}^{-1}\right)\end{array}$ & $\alpha$ & $\gamma$ & $\begin{array}{c}E_{\mathrm{c}} \\
(\mu \mathrm{mol} \\
\left.\mathrm{m}^{-2} \mathrm{~s}^{-1}\right)\end{array}$ \\
\hline Intact assemblage & $0.37 \pm 0.036$ & $-0.1 \pm 0.02$ & $0.001 \pm 0.002$ & $1 \times 10^{-4} \pm 0.001$ & $83 \pm 0.5$ \\
\hline Minus-Cystophora torulosa & $0.23 \pm 0.04$ & $-0.05 \pm 0.015$ & $9 \times 10^{-4} \pm 0.002$ & $-1 \times 10^{-4} \pm 0.001$ & $70 \pm 0.4$ \\
\hline Minus-Hormosira banksii & $0.28 \pm 0.03$ & $-0.05 \pm 0.013$ & $1 \times 10^{-3} \pm 0.0018$ & $-5 \times 10^{-4} \pm 0.001$ & $46 \pm 0.8$ \\
\hline Minus basal assemblage & $0.29 \pm 0.04$ & $-0.13 \pm 0.04$ & $1.4 \times 10^{-3} \pm 0.003$ & $3 \times 10^{-5} \pm 0.001$ & $72 \pm 0.4$ \\
\hline Basal assemblage & $0.1 \pm 0.05$ & $-0.04 \pm 0.02$ & $8 \times 10^{-4} \pm 0.003$ & $-1 \times 10^{-4} \pm 0.002$ & $35 \pm 0.8$ \\
\hline H. banksii & $0.25 \pm 0.04$ & $-0.14 \pm 0.03$ & $1.6 \times 10^{-3} \pm 0.002$ & $-5 \times 10^{-5} \pm 0.001$ & $69 \pm 0.6$ \\
\hline \multicolumn{6}{|l|}{ ANOVA } \\
\hline $\mathrm{p}$ & $<0.0001$ & $<0.0001$ & $<0.0001$ & $<0.0001$ & $<0.0001$ \\
\hline$F_{5,42}$ & 10.11 & 16.18 & 10.99 & 9.36 & 8.4 \\
\hline
\end{tabular}

C. torulosa treatment (Tukey's post-hoc test: $q=8.4$, $\mathrm{p}<0.001)$. Removal of both $C$. torulosa and the dominant $H$. banksii resulted in a further fall in net photosynthesis and a dramatic change in the dynamics of light use. In particular, there was a change from an almost linear relationship to a saturation curve. Tukey's post-hoc tests showed that $P_{2000}$ for this treatment was significantly lower than the intact assemblage $(q=9.8, \mathrm{p}<0.001)$, as well as a significant difference in $\gamma(q=7.1, p<0.001)$. Changing the removal order (Fig. 2B), by removing the dominant $H$. banksii first, resulted in a slightly different relationship. Again there was a significant effect of the minus-H. banksii treatment (Table 3). However, unlike the loss of $C$. torulosa, the loss of $H$. banksii from the assemblage was associated with a steeper increase in net photosynthesis at low irradiance $(\alpha)$ and higher photosynthesis at $300 \mu \mathrm{mol} \mathrm{m} \mathrm{m}^{-2} \mathrm{~s}^{-1}$, although this was not greatly different from the intact assemblage. However, there was a significant difference in the compensation point in these 2 assemblages (Tukey's post-hoc tests: $q=5.8, \mathrm{p}<0.01$ ). Conversely, net photosynthesis of the assemblage without H. banksii was significantly lower than the intact assemblage at $2000 \mu \mathrm{mol} \mathrm{m} \mathrm{m}^{-2} \mathrm{~s}^{-1}$ (Tukey's post-hoc test: $q=4.3, \mathrm{p}<0.05)$. However, when the basal assemblage was removed first (Fig. 2C), there was very little change in net photosynthesis, and although there was a slight drop at $2000 \mu \mathrm{mol} \mathrm{m} \mathrm{m}^{-2} \mathrm{~s}^{-1}$, this change was not significant. When both the basal assemblage and C. torulosa were removed (leaving only $H$. banksii), there was a larger drop in net photosynthesis at $2000 \mu \mathrm{mol} \mathrm{m} \mathrm{m}^{-2} \mathrm{~s}^{-1}$ (Tukey's post-hoc test: $q=4.3, \mathrm{p}<0.05)$. Although photoinhibition was seen in single-thallus incubations of $H$. banksii, an attached monoculture of $H$. banksii did not show the same fall in photosynthesis at high irradiance. Inter- estingly, the loss of C. torulosa had less of an impact on photosynthesis in this treatment, compared to where C. torulosa was the first species removed (Fig. 2A). This may be a real effect or could be related to slightly variable biomass of $C$. torulosa within these assemblages. Although the data were adjusted for biomass, higher amounts of the very productive $C$. torulosa could possibly skew results.

Comparing the net photosynthesis of the intact assemblage to the combined estimate of net photosynthesis of the 3 assemblage components showed 2 quite different $P-E$ relationships (Fig. 3). 'Additive net photosynthesis' is that of the 3 main components summed as a proportion of their contribution to the assemblage. This showed a typical saturation relationship and photoinhibition at high irradiance,

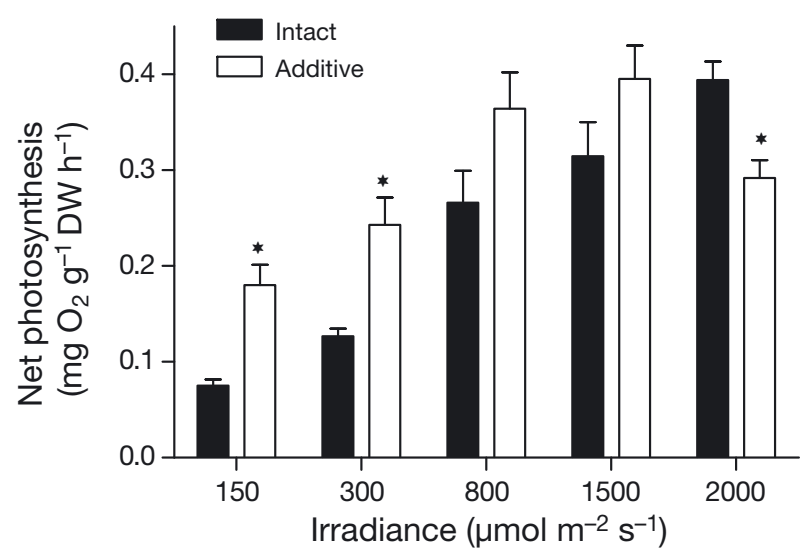

Fig. 3. Net photosynthesis $( \pm \mathrm{SE})$ of intact assemblages and additive net photosynthesis of separate components across irradiance levels. Additive net photosynthesis is the sum of the 3 main components of the assemblage (Hormosira banksii, Cystophora torulosa, and the Corallina officinalis assemblage) incubated alone. ${ }^{*}$ Significant differences within irradiance levels $(\mathrm{p}<0.05)$ 
whereas intact assemblages had a more linear increase in net photosynthesis with irradiance. Net photosynthesis was significantly different between intact vs. additive treatments $\left(F_{1,50}=12.49, \mathrm{p}<\right.$ $0.0001, \mathrm{n}=6$; 2-way ANOVA) and across irradiance levels $\left(F_{4,50}=29.5, \mathrm{p}<0.0001, \mathrm{n}=6\right)$. There was also a clear interaction among treatments and irradiance $\left(F_{4,50}=5.86, \mathrm{p}<0.001, \mathrm{n}=6\right)$. At lower irradiance, the additive net photosynthesis of the components was greater than for the intact assemblage $(150 \mu \mathrm{mol}$ $\mathrm{m}^{-2} \mathrm{~s}^{-1}: t=2.7, \mathrm{p}<0.05 ; 300 \mu \mathrm{mol} \mathrm{m}{ }^{-2} \mathrm{~s}^{-1}: t=3.0, \mathrm{p}<$ 0.05; Bonferroni post-hoc test). At $2000 \mu \mathrm{mol} \mathrm{m} \mathrm{m}^{-2} \mathrm{~s}^{-1}$, however, the net photosynthesis of the intact assemblage was higher than the additive net photosynthesis $(t=2.7, \mathrm{p}<0.05)$. Net photosynthesis at high irradiance is of particular interest, with the intact assemblage having higher photosynthetic rates than the sum of its parts, showing that an interaction between the species is enhancing photosynthesis of the assemblage.

There was a trend of increasing net photosynthesis with increasing canopy complexity, which was enhanced at higher levels of irradiance (Fig. 4). The greatest effect of canopy complexity on photosynthesis occurred at $2000 \mu \mathrm{mol} \mathrm{m} \mathrm{m}^{-2} \mathrm{~s}^{-1}$, with both the highest rate of net photosynthesis at 3 assemblage layers and the lowest at a single assemblage layer. Two-way ANOVA showed a significant effect of functional diversity on net photosynthesis $\left(F_{2,99}=24.4\right.$, $\mathrm{p}<0.0001$, $\mathrm{n}=12)$. There was also a significant interaction between canopy complexity and irradiance $\left(F_{4,99}=4.8\right.$, $\mathrm{p}<0.001, \mathrm{n}=12)$. Net photosynthesis at $2000 \mu_{\mathrm{mol} \mathrm{m}}{ }^{-2}$ $\mathrm{s}^{-1}$ was significantly greater than at $800 \mu \mathrm{mol} \mathrm{m} \mathrm{m}^{-2} \mathrm{~s}^{-1}$, when only 3 assemblage layers were present $(t=4.6$, $\mathrm{p}<0.0001$; Bonferroni post-hoc test). This indicates that canopies of varying complexity are affected in different ways, depending on the amount of light to which they are exposed.

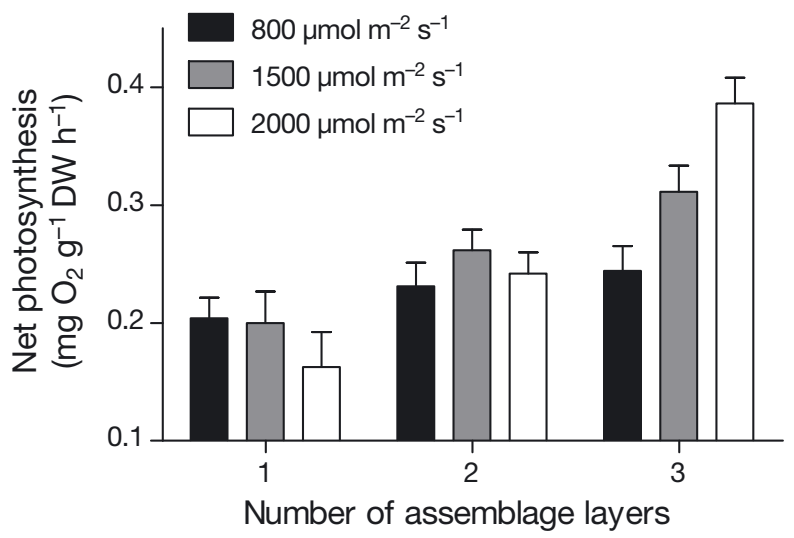

Fig. 4. Effects of assemblage complexity (number of canopy layers) on net photosynthesis $( \pm \mathrm{SE})$ at 3 levels of irradiance

\section{DISCUSSION}

The present study clearly showed that in contrast to the different components of assemblages, there were large differences in the $P-E$ relationships of intact assemblages. In particular, the ability not only to maintain net photosynthesis, but to increase the photosynthetic rate throughout the full range of natural irradiance shows remarkable efficiency of light use. Terrestrial research has shown that the photosynthetic production of leaves does not necessarily represent the productivity of whole plants (Beyschlag \& Ryel 1998) because relative productivity rates vary throughout the canopy layers and between tissue types. It would therefore seem intuitive that the same would hold for marine algal communities, which often comprise multiple canopy layers, yet a large majority of the photosynthetic research to date on marine macrophytes has considered single species or even single thalli (FloresMoya et al. 1995, Gómez et al. 1997). Although more recent studies have examined how light is used in assemblages (Middelboe \& Binzer 2004, Arenas et al. 2009), only one (Middelboe \& Binzer 2004) indicated a similar relationship between primary productivity and irradiance as seen in the present study.

The evidence from our study suggests that there is some level of complementarity within marine assemblages. The ability of an assemblage to increase net photosynthesis in a close-to-linear fashion implies a role of each component or canopy layer becoming important at different levels of irradiance. The loss of one or both canopy species leads to a change in the dynamics of photosynthesis. The loss of the less-dominant fucoid (Cystophora torulosa) has a significant effect on net photosynthesis at high irradiance, which may be related to its lack of photoinhibition at high irradiance and high photosynthetic potential. The removal of both fucoids affects the linearity of the $P$-E relationship. Complete loss of the canopy resulted in a change in the dynamics of light use, whereby net photosynthesis reverts to a saturation relationship instead of a linear relationship. When the removal order is changed and the dominant fucoid is removed first, the more productive C. torulosa enhances net photosynthesis at low irradiance, but due to a change in canopy complexity, photosynthesis is adversely affected at high irradiance. These results indicate that canopy structure is a very important factor, and should be considered in investigations testing the effects of species diversity on primary productivity. The effects of sub-canopy species losses show that basal species may be important at high levels of irradiance, but play only a minimal role in net photosynthesis at low irradiance where insufficient light penetrates through canopies. Canopy structure is, therefore, a key factor in testing the role of species complementarity across diver- 
sity levels. Random species mixtures, as used in many studies testing the influence of biodiversity on ecosystem function (Bruno et al. 2005), may eliminate the natural layering that occurs within natural canopies of macroalgae, and hence will be unable to detect important interactions among species and functional groups, particularly in terms of resource allocation.

The present study leads to the conclusion that layering within macroalgal assemblages plays a major role in maintaining net photosynthesis throughout the natural range of irradiance and even enhances photosynthetic rates at high irradiance. Furthermore, it is at high irradiance that canopy complexity has the largest influence on net photosynthesis. Although the effect of macroalgal biodiversity on primary productivity has been examined (Bruno et al. 2005), the role of light intensity has not been extensively tested. Because $P-E$ curves are fundamental to understanding the net photosynthesis in natural communities, it is essential that they be considered when examining functional relationships in layered communities. The magnitude of the effect of canopy complexity on photosynthesis is related to the variable light climate to which natural assemblages are exposed. Macroalgae have been shown to have an increased efficiency of light use under fluctuating light in certain cases (Dromgoole 1988, Wing et al. 1993, Kübler \& Raven 1996a,b). Natural variation in irradiance due to canopy movement could significantly enhance the steady-state photosynthesis of sub-canopy algae. Furthermore, the dominant period of ocean swells is typically within the 5 to $20 \mathrm{~s}$ range, and light flashes of this frequency have been shown to increase light-use efficiency significantly in macroalgae (Wing et al. 1993). The delivery of light flecks to the understory during canopy movement may prove to be an important process in overall assemblage production. The flecking of light caused by canopy movement at high irradiance may be an integral part of these systems and could enhance the contribution of sub-canopy species. As a consequence, the resource partitioning of assemblages may be misjudged because the main resource for which plant species compete has not been manipulated sufficiently. Despite light being the resource underpinning primary production, many studies testing the effects of biodiversity on ecosystem function have failed to manipulate it in any meaningful way. Although species diversity is not directly manipulated in the present study, the important roles of each canopy layer suggest that, to some degree, functional diversity may be essential for overall assemblage productivity.

There were also clues about other relevant mechanisms that may operate. The 3 dominant components of these intertidal communities varied in maximum rates of net photosynthesis. The mid-high shore envi- ronment that these species inhabit is subjected to a wide range of physiological stressors, in particular temperature, UV radiation, and high PAR irradiance. The $P$-E curves of each species reflect this habitat, showing saturation of photosynthesis at relatively high irradiance (cf. MacIntyre et al. 2002). Furthermore, photoinhibition is exhibited by 2 of the 3 components of the community, potentially reflecting an adaptation to high irradiance. High pigment density in low-lightadapted species elevates the risk of oxidative damage caused by reactive oxygen species at higher irradiance levels (Hanelt et al. 2003). The photoinhibition exhibited by Hormosira banksii and the basal assemblage can only be attributed to PAR irradiance as opposed to UV radiation (due to the calibration of the lamp used). The reduction in photosynthetic activity is most likely due to a down-regulation of the photosynthetic apparatus because the short incubation periods were most likely insufficient to cause significant photosynthetic damage (Häder \& Figueroa 1997). The lack of a photoinhibitory effect of high irradiance on Cystophora torulosa may indicate that it is unable to downregulate photosynthesis in the short term, and may be susceptible to higher levels of photosynthetic damage. This hypothesis is potentially corroborated by the occurrence of an annual burn-off of C. torulosa from the more exposed areas of the intertidal zone over the summer months (Lilley \& Schiel 2006).

The present study reinforces the need to examine communities in their naturally structured states, as suggested by others (Bracken et al. 2008, Stachowicz et al. 2008), rather than in random assemblages. Although our study was done in controlled laboratory conditions, it considers natural species composition and structure, particularly canopy layering. These results add a new dimension to biodiversity-function research on primary production in the marine environment and indicate the complexity of biological communities. Light, the primary resource for photosynthesizing organisms, is likely to be critical in uncovering an effect of diversity on function within autotrophic communities. Canopy structure and light delivery are vital to sub-canopy production within tropical forest ecosystems (Chazdon \& Pearcy 1991, Valladares et al. 1997), and it appears that a similar process operates in marine macroalgal assemblages. The delivery of light flecks to the understory during canopy movement may prove to be an important process in overall assemblage production. Of course, this needs further elaboration through in situ tests where light delivery may be more complicated. If ecosystems as different as intertidal macroalgal assemblages and terrestrial rainforests show similarities in light use, then canopy structure may play an essential role in the enhancement of primary production at high biodiversity in natural communities. 
Acknowledgements. We thank Dr. M. Forster for guidance and critical comments on the manuscript, members of the Marine Ecology Research Group for all manner of assistance, the University of Canterbury post-graduate fund for scholarship support, the 2 anonymous reviewers for their helpful and constructive comments, and the Andrew W. Mellon Foundation of New York and the New Zealand Foundation for Research, Science and Technology (Coasts and Oceans OBI, grants C01X0307 and C01X0501) for program support.

\section{LITERATURE CITED}

> Arenas F, Rey F, Pinto IS (2009) Diversity effects beyond species richness: evidence from intertidal macroalgal assemblages. Mar Ecol Prog Ser 381:99-108

Arkema KK, Reed DC, Schroeter SC (2009) Direct and indirect effects of giant kelp determine benthic community structure and dynamics. Ecology 90:3126-3137

Bertness MD, Leonard GH, Levine JM, Schmidt PR, Ingraham AO (1999) Testing the relative contribution of positive and negative interactions in rocky intertidal communities. Ecology 80:2711-2726

Beyschlag WR, Ryel RJ (1998) Modeling leaf/canopy photosynthesis. In: Raghavendra AS (ed) Photosynthesis: a comprehensive treatise. Cambridge University Press, Cambridge, p 305-319

Binzer T, Sand-Jensen K (2002) Importance of structure and density of macroalgae communities (Fucus serratus) for photosynthetic production and light utilisation. Mar Ecol Prog Ser 235:53-62

Bracken MES, Stachowicz JJ (2006) Seaweed diversity enhances nitrogen uptake via complementary use of nitrate and ammonium. Ecology 87:2397-2403

Bracken MES, Friberg SE, Gonzalez-Dorantes CA, Williams SL (2008) Functional consequences of realistic biodiversity changes in a marine ecosystem. Proc Natl Acad Sci USA 105:924-928

Bruno JF, Stachowicz JJ, Bertness MD (2003) Inclusion of facilitation into ecological theory. Trends Ecol Evol 18: 119-125

Bruno JF, Boyer KE, Duffy JE, Lee SC, Kertesz JS (2005) Effects of macroalgal species identity and diversity on primary productivity in benthic marine communities. Ecol Lett 8:1165-1174

> Chazdon RL, Pearcy RW (1991) The importance of sunflecks for forest understory plants. BioScience 41:760-766

Dromgoole FI (1988) Light fluctuations and the photosynthesis of marine algae. II. Photosynthetic response to frequency, phase ratio and amplitude. Funct Ecol 2:211-219

Flores-Moya A, Fernández JA, Niell FX (1995) Seasonal variations of photosynthetic pigments, total C, N and P content and photosynthesis in Phyllariopsis purpurascens: (Phaeophyta) from the Strait of Gibraltar. J Phycol 31:867-874

Golléty C, Migné A, Dominique D (2008) Benthic metabolism on a sheltered rocky shore: role of the canopy in the carbon budget. J Phycol 44:1146-1153

Gómez I, Weykam G, Klöser H, Wiencke C (1997) Photosynthetic light requirements, metabolic carbon balance and zonation of sublittoral macroalgae from King George Island (Antarctica). Mar Ecol Prog Ser 148:281-293

Häder DP, Figueroa FL (1997) Photoecophysiology of marine macroalgae. Photochem Photobiol 66:1-14

Hanelt D, Wiencke C, Bischof PK (2003) Photosynthesis in marine macroalgae. In: Larkum AWD, Douglas SE, Raveb JA (eds) Photosynthesis in algae. Kluwer Academic, Dordrecht
Huston MA (1997) Hidden treatments in ecological experiments: re-evaluating the ecosystem function of biodiversity. Oecologia 100:449-460

> Huston MA, Aarssen LW, Austin MP, Cade BS and others (2000) No consistent effect of plant diversity on productivity. Science 289:1255

Keough MJ, Quinn GP (1998) Effects of periodic disturbances from trampling on rocky intertidal algal beds. Ecol Appl 8:141-161

Kingsford MJ, Underwood AJ, Kennelly SJ (1991) Humans as predators on rocky reefs in New South Wales, Australia. Mar Ecol Prog Ser 72:1-14

$>$ Kübler JE, Raven JA (1996a) Nonequilibrium rates of photosynthesis and respiration under dynamic light supply. J Phycol 32:963-969

> Kübler JE, Raven JA (1996b) Inorganic carbon acquisition by red seaweeds grown under dynamic light regimes. Hydrobiologia 326/327:401-406

Larkum AWD (1986) A study of growth and primary production in Ecklonia radiata at a sheltered site in Port Jackson, New South Wales. J Exp Mar Biol Ecol 96:177-190

Lilley SA, Schiel DR (2006) Community affects following the deletion of habitat-forming alga from rocky marine shores. Oecologia 148:672-681

> Littler MM, Arnold KE (1982) Primary productivity of marine algal functional-form groups from south-western North America. J Phycol 18:307-311

Littler MM, Littler DS (1980) The evolution of thallus form and survival strategies in benthic marine macroalgae: field and laboratory tests of a functional form model. Am Nat 116:25-44

MacIntyre HL, Kana TM, Anning T, Geider RJ (2002) Photoacclimation of photosynthesis irradiance response curves and photosynthetic pigments in microalgae and cyanobacteria. J Phycol 38:17-38

Mann KH (1972) Ecological energetics of the sea-weed zone in a marine bay on the Atlantic coast of Canada. II. Productivity of the seaweeds. Mar Biol 14:199-209

Mann KH (1973) Seaweeds: their productivity and strategy for growth. Science 182:975-981

> Middelboe AL, Binzer T (2004) Importance of canopy structure on photosynthesis in single- and multi-species assemblages of marine macroalgae. Oikos 107:422-432

Schiel DR (1990) Macroalgal assemblages in New Zealand: structure, interactions and demography. Hydrobiologia 192:59-76

> Schiel DR (2006) Rivets or bolts? When single species count in the function of temperate rocky reef communities. J Exp Mar Biol Ecol 338:233-252

Schiel DR, Taylor DI (1999) Effects of trampling on a rocky intertidal algal assemblage in southern New Zealand. J Exp Mar Biol Ecol 235:213-235

Schiel DR, Wood SA, Dunmore RA, Taylor DI (2006) Sediment on rocky intertidal reefs: effects on post-settlement stages of habitat forming seaweeds. J Exp Mar Biol Ecol 331: 158-172

> Shaver GR, Canadell J, Chapin FS, Gurevitch J and others (2000) Global warming and terrestrial ecosystems: a conceptual framework for analysis. BioScience 50:871-882

Stachowicz JJ, Bruno JF, Duffy JE (2007) Understanding the effects of marine biodiversity on communities and ecosystems. Annu Rev Ecol Evol Syst 38:739-766

> Stachowicz JJ, Best RJ, Bracken MES, Graham MH (2008) Complementarity in marine biodiversity manipulations: reconciling divergent evidence from field and mesocosm experiments. Proc Natl Acad Sci USA 105:18842-18847

Tait LW, Schiel DR (2010) Primary productivity of intertidal 
macroalgal assemblages: comparison of laboratory and in situ photorespirometry. Mar Ecol Prog Ser 416:115-125

Tilman D, Knops J, Wedin D, Reich P, Ritchie M, Siemann E (1997) The influence of functional diversity and composition on ecosystem processes. Science 277:1300-1302

Underwood AJ (1998) Grazing and disturbance: an experimental analysis of patchiness in recovery from a severe storm by the intertidal alga Hormosira banksii on rocky shores in New South Wales. J Exp Mar Biol Ecol 231: 291-306

Editorial responsibility: Rodney Forster,

Lowestoft, UK
Valladares F, Allen MT, Pearcy RW (1997) Photosynthetic responses to dynamic light under field conditions in six tropical rainforest shrubs occurring along a light gradient. Oecologia 111:505-514

Walsby AE (1997) Numerical integration of phytoplankton photosynthesis through time and depth in a water column. New Phytol 136:189-209

Wing SR, Leichter JJ, Denny MW (1993) A dynamic model for wave-induced light fluctuations in a kelp forest. Limnol Oceanogr 38:386-407

Submitted: March 26, 2010; Accepted: October 11, 2010

Proofs received from author(s): December 20, 2010 